\title{
Hiperkarbik Solunum Yetmezliğinde Noninvaziv Mekanik Ventilasyon Başarısızlığı ve Başarısızlığın Uzun Dönem Takip Sonuçları
}

\author{
Noninvasive Mechanical Ventilation Failure and Long-Term Follow-up Results of Failure in \\ Hypercarbic Respiratory Failure
}

\author{
Eylem ACARTÜRK TUNÇAY \\ (1) 0000-0002-5046-1943 \\ Sinem GÜNGÖR \\ (1) 0000-0002-1163-125X \\ Birsen OCAKLI \\ (1) 0000-0001-6145-8638
}

Sağlık Bilimleri Üniversitesi,

Süreyyapaşa Gögüs Hastalıkları ve Gögüs Cerrahisi Eğitim ve Araştırma Hastanesi, İstanbul

\section{Sorumlu Yazar \\ Corresponding Author \\ Birsen OCAKLI \\ birsenocakli@hotmail.com}

Geliș Tarihi / Received : 16.12 .2018

Kabul Tarihi / Accepted : 22.04.2019

Çevrimiçi Yayın Tarihi /

Available Online

\section{Öz}

Amaç: Akut solunum yetmezliğinde noninvaziv mekanik ventilasyon (NIMV) kullanımı önemli bir seçenek haline gelmiştir. Bu çalışmanın amacı hiperkarbik solunum yetmezliği (HSY)'nde NIMV başarısızlık sebepleri ve takip sonuçlarının değerlendirilmesidir.

Gereç ve Yöntemler: Geriye dönük gözlemsel kohort çalışma üçüncü basamak göğüs hastalıkları hastanesinin yoğun bakım ünitesinde yapıldı. HSY ile NIMV başarısızlığı olan Ocak-Aralık 2016 arasındaki tüm hastalar çalışmaya alındı. Erken ve geç NIMV başarısızlığ 1 olan gruplarda demografik özellikler, yoğun bakım verileri ve mortalite incelendi. Verilerin analizinde uygun istatistiksel test ve analizler kullanıldı.

Bulgular: Çalışmaya alınan 218 hastanın büyük çoğunluğu (n=158, \%72,5) kronik obstrüktif akciğer hastalığı idi. Olguların \%56'sında erken dönem NIMV başarısızlığı görülmekteydi. En sık görülen başarısızlık nedenleri asidozun devam etmesi veya derinleşmesi ve parsiyel karbondioksit basıncında artış olmasıydı. Mortalite, yoğun bakımda $\% 20$, taburculuk sonrası 28 günde ise $\% 9$ olarak saptandı. NIMV başarısızlığını asidozun devam etmesinin 4,1 kat (\%95 güven aralığ $(\mathrm{GA}) 1,711-9,882 ; \mathrm{p}=0,002)$, hava yolunu koruyamamanın 10,4 kat (\%95 GA $1,224-89,264 ; \mathrm{p}=0,032)$, bilinç bulanıklığının ise 2,3 kat (\%95 GA 1,023-5,295; $\mathrm{p}=0,044)$ artırdığı bulundu.

Sonuç: Bu çalışmada olguların yarısında erken NIMV başarısızlığı görülmüş olup en sık başarısızlık sebeplerinin ise asidozun devam etmesi ve parsiyel karbondioksit basıncında artma olduğu bulundu. Yoğun bakım ve 28 günlük mortaliteler değerlendirildiğinde, NIMV başarısızlığı olan hastaların yoğun bakımdan taburcu olduktan sonra da yakın takip edilmesi gerektiği düşünülmektedir.

Anahtar kelimeler: Noninvaziv ventilasyon; solunum yetmezliği; yoğun bakım; tedavi başarısızlığı.

\footnotetext{
ABSTRACT

Aim: Use of noninvasive mechanical ventilation (NIMV) in acute respiratory failure has been an important option. The aim of this study is to evaluate causes of NIMV failure and followup results in hypercarbic respiratory failure (HRF).

Material and Methods: Retrospective observational cohort study was performed in intensive care unit of tertiary chest disease hospital. All patients with NIMV failure due to HRF between January-December 2016 were included in the study. Demographic characteristics, intensive care data and mortality were evaluated in early and late NIMV failure groups. Appropriate statistical tests and analyzes were used for analysis of data.

Results: The majority of 218 patients $(n=158,72.5 \%)$ included in the study was chronic obstructive pulmonary disease. Early NIMV failure was seen $56 \%$ of cases. The most common causes of failure were progression or worsening of acidosis and increase in partial carbon dioxide pressure. Mortality was detected as $20 \%$ in intensive care unit and $9 \%$ after discharge in 28-days. Factors increased NIMV failure was found as progression of acidosis by 4.1 fold (95\% confidence interval (CI) $1.711-9.882, \mathrm{p}=0.002$ ), inability to protect airway by 10.4 fold $(95 \%$ CI $1.224-89.264, p=0.032)$ and blurred consciousness by 2.3 fold (95\% CI $1.023-5.295$, $\mathrm{p}=0.044)$.

Conclusion: Early NIMV failure was observed in half of cases and most common causes of failure were found as progression of acidosis and increase in partial carbon dioxide pressure. When intensive care and 28-day mortality are evaluated, it is thought that patients with NIMV failure should be followed-up closely after discharge from intensive care.

: 25.04.2019 Keywords: Noninvasive ventilation; respiratory failure; intensive care; treatment failure.
} 


\section{GÍRIŞ}

Akut solunum yetmezliğinde seçilmiş hasta gruplarında noninvaziv mekanik ventilasyon (NIMV) kullanımı günümüzde giderek artmaktadır (1). NIMV ile entübasyon oranının azaldığı, yoğun bakım yatış süresinin kısaldığı ve mortalitenin azaldığı bildirilmektedir. Aynı zamanda NIMV yoğun bakım ünitesi (YBÜ) dışında, acil serviste ve serviste de uygulanabilmekte olup, uygulama esnasinda sedasyona gerek duyulmamaktadır. Hasta konforu açısından avantajlıdır. Bilinci açık olan, havayolunu koruyan, klinik açıdan stabil olan ve maske uygulanması için kontrendikasyon olmayan hastalar NIMV için uygundur (2).

Uygun hasta ve klinik endikasyonla başlandığında NIMV çoğunlukla solunum yetmezliği tedavisinde başarılı bir yöntemdir. NIMV başarısının en önemli göstergeleri solunum sayısı ve $\mathrm{PaCO}_{2}$ değerinde düşme, $\mathrm{pH}$ ve oksijenasyonda düzelmedir (3). Altta yatan nedene göre değişmekle beraber NIMV başarısızlığı \%5-60 olarak bildirilmiştir (1,4-6). NIMV başarısızlığı endotrakeal entübasyon veya ölüm olarak tanımlanmaktadır (7). NIMV başarı ve başarısızlığı ile ilgili çok çeşitli çalışmalar mevcut olup bu çalışmalarda NIMV endikasyonları, komplikasyonları, başarı ve başarısızlığını etkileyen faktörler incelenmiştir (4-8). Yapılan çalışmalarda dakikalar ile bir saat içinde ortaya çıkan başarısızlıklar hızlı başarısızlık, 1-48 saat içerisinde ortaya çıkan başarısızlıklar erken başarısızlık, 48 saatten sonra ortaya çıkan başarısızlıklar ise geç başarısızlık olarak tanımlanmıştır $(8,9)$.

Bu çalışmada, hiperkarbik solunum yetmezliği (HSY)'nde NIMV başarısızlığı ve başarısızlığın uzun dönem takip sonuçlarının değerlendirilmesi amaçlanmıştır.

\section{GEREÇ VE YÖNTEMLER}

Geriye dönük gözlemsel kohort tipindeki bu çalışma Sağlık Bilimleri Üniversitesi Süreyyapaşa Göğüs Hastalıkları ve Göğüs Cerrahisi Eğitim ve Araştırma Hastanesi, Solunumsal Yoğun Bakım Ünitesinde yapıldı. HSY nedeniyle YBÜ'ye başvuran, NIMV başarısızlığ (ölüm ya da entübasyon) olan Ocak 2016 ile Aralık 2016 arasındaki tüm hastalar çalışmaya alındı. Helsinki deklarasyonu ile uyumlu olarak, çalışma için Sağlık Bilimleri Üniversitesi Süreyyapaşa Göğüs Hastalıkları ve Göğüs Cerrahisi Eğitim ve Araştırma Hastanesi Etik Kurulundan 05.10.2018 tarih ve 050 sayılı karar ile onay alındı. Çalışma geriye dönük olduğu için hastalardan aydınlatılmış onam alınamadı ancak hasta kimlik bilgileri gizlendi.

Hastaların demografik özellikleri yanında, ek hastalıkları, HSY nedenleri, arter kan gazı (AKG), APACHE II, Glaskow koma skalası (GKS), YBÜ yatış günü, uzun ve kısa dönem mortalitesi ve NIMV başarısızlık nedenleri kaydedildi.

\section{Hastalar}

HSY nedeniyle YBÜ'ye başvuran hastalar içerisinde NIMV uygulanması için uygun olanlar çalışmaya alındı. HSY ile yoğun bakıma başvuran olguların hepsine NIMV'ye ek olarak standart medikal tedavi (oksijen desteği, gerekli durumlarda sistemik kortikosteroid, inhale bronkodilatör ilaçlar, antibiyotik ve diüretik) uygulandı. Solunum fizyoterapisti tarafindan olgulara, solunum fizyoterapi desteği verildi.

\section{Çalışmaya Alınma Kriterleri}

- 18 yaşından büyük hastalar

- HSY olan hastalar

- Bilinci açık (GKS: 15) hastalar

- Yeterli öksürük refleksi ve yutma fonksiyonu olan hastalar

- Hemodinamik olarak stabil hastalar

- Maske-yüz uyumu olan hastalar

Çalışmaya Alınmama Kriterleri

- Pnömotoraks

- Sekresyonlarinı atamayan ve havayolunu koruyamayan olgular

- NIMV uygulaması esnasinda koopere olamayan olgular

- Yüz deformitesi olan olgular

- Tedavisi devam etmekte iken kendi isteği ile taburcu olan olgular

\section{Tanımlar}

Solunum Yetmezliği

- $\mathrm{pH}<7,35, \mathrm{PaCO}_{2}>45 \mathrm{mmHg}, \mathrm{PaO}_{2}<55 \mathrm{mmHg}$ veya $\mathrm{PaO}_{2} / \mathrm{FiO}_{2} \leq 200$ olmas 1

- Klinik olarak solunum sayısının 25/dk'nın üzerinde olmas1,

- Parodoksal solunum, yardımeı solunum kas kullanımı olarak tanımlandı (10).

NIMV endikasyonlart

- Yardımcı solunum kaslarının kullanılmasını gerektiren ve paradoksal karın hareketlerine yol açan orta ve ağır dispne,

- Takipne (>25/dakika),

- $\mathrm{AKG}$ 'de $\mathrm{pH}<7,35, \mathrm{pCO}_{2}>45 \mathrm{mmHg}$ veya $\mathrm{PaO}_{2} / \mathrm{FiO}_{2}<200 \mathrm{mmHg}$

$\mathrm{Bu}$ parametrelerden en az ikisinin olması yeterlidir (11).

\section{NIMV Uygulaması}

Olgulara yoğun bakım ventilatörü ile NIMV uygulandi. Olguların toleransına ve yüz uygunluğuna göre oronasal veya tam yüz maskesi tercih edildi. Olguların yemek yeme ve su içmesi, balgam çıkarması için NIMV'ye ara verildi. Klinik ve $A K G$ değerleri düzeldikçe NIMV süresi kısaltıldı. Pozitif inspiratuar havayolu basıncı (IPAP), hasta tolere edebildiği müddetçe $7-10 \mathrm{ml} / \mathrm{kg}$ tidal volüm oluşturacak şekilde ayarland1. Ekspiryum sonu pozitif basınç ise başlangıç değeri $5 \mathrm{~cm} \mathrm{H}_{2} \mathrm{O}$ olacak şekilde ayarland 1 ve $\mathrm{FiO}_{2}$ ihtiyac1 $<0,50$ olana kadar $1 \mathrm{~cm} \mathrm{H}_{2} \mathrm{O}$ artırıld. NIMV uygulanırken nemlendirici kullanılmadı.

\section{Oksijen Tedavisi}

Hastalara oksijen satürasyonu $>\% 88-90$ olacak şekilde oksijen tedavisi verildi.

\section{NIMV başarısızlığı}

NIMV başarısızlığı ise NIMV veya esnasında olgunun eksitus olması veya olguda invaziv mekanik ventilasyon ihtiyacının olması olarak tanımlandı (7).

Entübasyon İhtiyace

- NIMV altında $\mathrm{PaCO}_{2}$ basıncinın artması ( $\geq 6 \mathrm{mmHg}$ ) ve $\mathrm{pH}$ 'nın düşmesi $(\mathrm{pH} \leq 0,04)$

- Havayolunu koruyamaya (koma, epileptik nöbet) ve yoğun sekresyon artışına bağlı NIMV uygulanamaması

- Hemodinamik instabilite (uyanıklığın azalması ve nabız dakika sayısı $<50$ atım/dk olması sistolik kan basıncinın $<70 \mathrm{mmHg}$ olmasi)

- Maskeyi tolere edemeyecek seviyede ajitasyon (12). 
NIMV uygulamasindan sonra 48 saat içinde NIMV başarısızlığı gelişirse erken NIMV başarısızlığı olarak, eğer 48 saatten sonra gelişirse geç NIMV başarısızlığ olarak tanımland $1(8,9)$.

\section{İstatistiksel Analiz}

Çalışmada elde edilen verilerin istatistiksel analizleri için SPSS (Statistical Package for Social Sciences) for Windows 20.0 programı kullanıldı. Hastaların demografik ve klinik verilerini değerlendirmek için tanımlayıcı istatistikler hesapland1. Kolmogorov-Smirnov testi yapılarak normal dağılım kontrol edildi. Normal dağılım gösteren sürekli değişkenlerde Student's t-testi kullanılarak değerler ortalama ve standart sapma ile gösterildi. Normal dağılım göstermeyen sürekli değişkenlerde Mann Whitney-U kullanıld1, değerler ortanca ve çeyreklikler (1. ve 3. çeyrek değerleri) ile gösterildi. Kategorik değişkenler arasındaki ilişkiler Pearson Ki-kare ve Fisher's Exact testleri ile değerlendirildi. Geç dönemde NIMV başarısızlığı risk analizi için çoklu lojistik regresyon analizi uygulandi. Çoklu lojistik regresyon analizinde, bağımlı değişken geç dönemde görülen NIMV başarısızlığı idi. Tek değişkenli analizlerde anlamlı olanlar ile literatürdeki çalışmalardan geç dönemde başarısızlığa neden olabileceği bilinen nedenler modele bağımsız değişken olarak dahil edildi. Modelin uygunluğu için Hosmer \& Lemeshow testi ve Nagelkerke $\mathrm{R}^{2}$ değeri kullanıldı. Sonuçlar $\% 95$ güven aralığı (GA)'nda değerlendirildi. İstatistiksel anlamlılık düzeyi 0.05 olarak dikkate alındı.

\section{BULGULAR}

Çalışmaya YBÜ'de NIMV uygulanan 218 olgu alındı. Olguların \%57,8'i erkek olup yaş ortalaması 70,5 $\pm 11,4$ idi. Yetmiş iki olgu aktif sigara içicisi idi. Ek hastalıklar değerlendirildiğinde 186 olguda en az bir ek hastalık varlığı söz konusu olup en sık hipertansiyon (\%49,5), daha sonra sırasıyla konjestif kalp yetmezliği $(\% 29,8)$ ve diyabetes mellitus $(\% 28,4)$ görülmekteydi. Olguların tüm demografik özellikleri Tablo 1'de özetlenmiştir.

Tablo 1. Olguların demografik özellikleri $(n=218)$

\begin{tabular}{lc}
\hline Demografik Özellikler & n (\%) \\
\hline Yaş (yıl), ortalama $\pm \mathrm{SS}$ & $70,5 \pm 11,4$ \\
Beden Kitle indeksi $\left(\mathrm{kg} / \mathrm{m}^{2}\right)$, ortanca $(\mathrm{C} 1-C ̧ 3)$ & $23(20-28)$ \\
Cinsiyet & \\
Erkek & $126(57,8)$ \\
Kadın & $92(42,2)$ \\
Aktif sigara içici & $72(33,0)$ \\
Biyomas & $17(7,8)$ \\
Ek hastalık varlığı* & $186(85,3)$ \\
Konjestif kalp yetmezliği & $65(29,8)$ \\
Diyabetes mellitus & $62(28,4)$ \\
Hipertansiyon & $108(49,5)$ \\
Koroner arter hastalığ & $37(17,0)$ \\
Atriyal fibrilasyon & $37(17,0)$ \\
Kronik böbrek yetmezliği & $20(9,2)$ \\
Malignite & $25(11,5)$ \\
Uzun süreli oksijen tedavisi & $138(63,3)$ \\
Evde non-invaziv mekanik ventilasyon & $66(30,3)$ \\
\hline *: Birden fazla ek hastalı̆̆ı bulunan olgu mevcuttur, SS: Standart sapma, &
\end{tabular}

Olguların yoğun bakım yatış anındaki verileri değerlendirildiğinde, yoğun bakım ağırlığını gösteren skor olan APACHE II ortancası 26 bulundu. Yoğun bakımda hiperkarbik solunum yetmezliği nedeniyle NIMV uygulanan olguların büyük çoğunluğunu kronik obstrüktif akciğer hastalığı $(\mathrm{KOAH}, \mathrm{n}=158, \% 72,5)$ oluşturmakta olup, onu siklık sirasına göre obezite hipoventilasyon sendromu (OHS, $n=18, \% 8,3)$, bronşektazi $(n=13, \% 6)$, pnömoni $(\mathrm{n}=9, \% 4,1)$, malignite $(\mathrm{n}=8, \% 3,7)$, interstisyel akciğer hastalığ $(\dot{\mathrm{I} A H}, \mathrm{n}=7, \% 3,2)$ ve kifoskolyoz $(\mathrm{n}=5$, $\% 2,3$ ) izlemekteydi. Olguların YBÜ yatış süresi ortalaması $13,9 \pm 0,7$ idi ve yoğun bakımda yatarken mortalite $\% 20$ olarak saptand. Taburculuk sonrası 28 günlük mortalite ise $\% 9$ idi. Olguların YBÜ verileri Tablo 2'de özetlenmiştir.

NIMV başarısızlık nedenleri incelendiğinde en sık başarısızlık sebebinin AKG'de asidozun devam etmesi ve parsiyel karbondioksit basıncında artma olduğu bulundu. NIMV başarısızlık nedenleri Tablo 3 'te özetlenmiştir.

Tablo 2. Olguların yoğun bakım verileri $(n=218)$

\begin{tabular}{|c|c|}
\hline APACHE II, ortanca (Ç1-Ç3) & $26(22-29)$ \\
\hline Charlson indeksi, ortanca (Ç1-Ç3) & $5(4-6)$ \\
\hline Glaskow koma skalası, ortalama \pm SS & $14,3 \pm 0,1$ \\
\hline $\begin{array}{l}\text { Tanılar, } \mathrm{n}(\%) \\
\text { Kronik obstrüktif akciğer hastalığ1 } \\
\text { Obezite hipoventilasyon sendromu } \\
\text { Bronşektazi } \\
\text { Pnömoni } \\
\text { Malignite } \\
\text { İterstisyel akciğer hastalığ }{ }_{1} \\
\text { Kifoskolyoz }\end{array}$ & $\begin{array}{c}158(\% 72,5) \\
18(\% 8,3) \\
13(\% 6,0) \\
9(\% 4,1) \\
8(\% 3,7) \\
7(\% 3,2) \\
5(\% 2,3)\end{array}$ \\
\hline $\begin{array}{l}\text { Yatış arteryel kan gazı değerleri } \\
\mathrm{pH} \text {, ortanca }(\mathrm{C} 1-\mathrm{Ç} 3) \\
\mathrm{PaCO}_{2}(\mathrm{mmHg}) \text {, ortanca }(\mathrm{Ç} 1-\mathrm{C} 3) \\
\mathrm{PaO}_{2} / \mathrm{FiO}_{2} \text {, ortanca }(\mathrm{C} 1-\mathrm{C} 3)\end{array}$ & $\begin{array}{l}7,28(7,23-7,32) \\
71(61-82) \\
202(163-272)\end{array}$ \\
\hline Erken başarısızlık, n (\%) & $124(\% 56,8)$ \\
\hline Geç başarısızlık, n (\%) & $94(\% 43,1)$ \\
\hline Yoğun bakım yatış süresi (gün), ortalama \pm SS & $13,9 \pm 0,7$ \\
\hline Yoğun bakımda mortalite, n (\%) & $44(\% 20,2)$ \\
\hline Taburculuk sonrası 28 günde mortalite, $\mathrm{n}(\%)$ & $19(\% 8,7)$ \\
\hline
\end{tabular}

Tablo 3. NIMV başarısızlık nedenleri*

\begin{tabular}{lc}
\hline Nedenler & n (\%) \\
\hline Arter kan gazında asidoz devam etmesi & $127(58,3)$ \\
Asidozun derinleşmesi & $111(50,9)$ \\
$\mathrm{PaCO}_{2}$ artışı & $99(45,4)$ \\
Solunum arresti & $88(40,4)$ \\
Maske intoleransı & $49(22,5)$ \\
Hemodinamik instabilite & $41(18,8)$ \\
Bilinç bulanıklığı & $38(17,4)$ \\
Ajitasyon/deliryum & $21(9,6)$ \\
Hava yolunu koruyamama & $10(4,6)$
\end{tabular}

*: Birden fazla neden olan olgu mevcuttur, NIMV: Noninvaziv mekanik ventilasyon, $\mathrm{PaCO}_{2}$ : Parsiyel karbondioksit basinc1 
Erken ve geç dönemde NIMV başarısızlığı olan grupların demografik özellikleri ve yoğun bakım verilerinin karşılaştırılması Tablo 4'te verilmiştir. APACHE II skoru, erken dönemde NIMV başarısızlığı olan grupta 28 (24-31) geç dönemde NIMV başarısızlığı olan gruptan 23 (21-27) daha yüksekti $(p<0,001)$. Erken ve geç dönemde NIMV başarısızlığı olan gruplarda SOFA skorları (sırasıyla, 10 (7-12) ve 10 (10-11)) arasinda anlamlı farklılık yoktu $(\mathrm{p}=0,476)$. Erken dönemde akut solunum sıkıntısı sendromu (ARDS) görülme oranı $(n=7, \% 5,6)$ geç döneme göre daha fazlaydı $(p=0,020)$. Erken dönemde NIMV başarısızlığı olan grupta $\mathrm{pH}$ değeri $(7,27 \pm 0,05)$ geç döneme göre $(7,31 \pm 0,07)$ daha düşüktü $(p<0,001)$. Yoğun bakım yatış süresi geç dönemde NIMV başarısızlığı olan grupta (13 (9-21) gün), erken döneme göre (10 (6-15) gün) daha uzun idi $(\mathrm{p}=0,001)$. Erken ve geç dönemde NIMV başarısızlığı olan gruplarda yoğun bakım mortalitesi karşılaştırıldığında istatistiksel olarak anlamlı farklılık saptanmamıştır $(\mathrm{p}=0,170)$.

Erken ve geç dönemde NIMV başarısızlığı olan gruplar tanı ve ek hastalıklara göre karşılaştırıldığında istatistiksel olarak anlamlı bir farklılık saptanmamıştır (Tablo 4).

Tablo 4. Erken ve geç dönemde NIMV başarısızlığı olan grupların demografik özellikleri, yoğun bakım verileri, tanı ve ek hastalıklarının karşılaştırılması

\begin{tabular}{|c|c|c|c|}
\hline & $\begin{array}{c}\text { Erken NIMV Başarısızlığı } \\
(\mathrm{n}=124)\end{array}$ & $\begin{array}{c}\text { Geç NIMV Başarısızlığ } \\
(\mathrm{n}=94)\end{array}$ & $\mathbf{p}$ \\
\hline Yaş (yıl), ortalama \pm SS & $71,8 \pm 11,6$ & $70,2 \pm 11,2$ & 0,690 \\
\hline \multicolumn{4}{|l|}{ Cinsiyet, n (\%) } \\
\hline Erkek & $72(58,1)$ & $54(57,4)$ & \multirow{2}{*}{0,927} \\
\hline Kadın & $52(41,9)$ & $40(42,6)$ & \\
\hline Beden kitle indeksi $\left(\mathrm{kg} / \mathrm{m}^{2}\right)$, ortalama $\pm \mathrm{SS}$ & $27,1 \pm 7,8$ & $25,0 \pm 7,1$ & $\mathbf{0 , 0 3 8}$ \\
\hline \multicolumn{4}{|l|}{ Sigara Kullanımı, n (\%) } \\
\hline Aktif sigara içici & $40(32,2)$ & $32(34,0)$ & \multirow{3}{*}{0,894} \\
\hline Bırakmış & $42(33,9)$ & $29(30,9)$ & \\
\hline Sigara içmeyen & $42(33,9)$ & $33(35,1)$ & \\
\hline Biyomas maruziyeti, n (\%) & $5(4,0)$ & $12(12,8)$ & $\mathbf{0 , 0 1 7}$ \\
\hline Glaskow koma skalası, ortalama \pm SS & $14,2 \pm 1,6$ & $14,2 \pm 1,9$ & 0,284 \\
\hline APACHE II, ortanca (Ç1-Ç3) & $28(24-31)$ & $23(21-27)$ & $<\mathbf{0 , 0 0 1}$ \\
\hline $\mathrm{pH}$, ortalama $\pm \mathrm{SS}$ & $7,27 \pm 0,05$ & $7,31 \pm 0,07$ & $<0,001$ \\
\hline $\mathrm{PaCO}_{2}(\mathrm{mmHg})$, ortalama $\pm \mathrm{SS}$ & $73,1 \pm 16,7$ & $72,0 \pm 14,7$ & 0,616 \\
\hline $\mathrm{PaO}_{2} / \mathrm{FiO}_{2}$, ortanca $(\mathrm{C} 1-C ̧ 3)$ & $169(126-230)$ & $177(139-258)$ & 0,156 \\
\hline SOFA, ortanca (Ç1-Ç3) & $10(7-12)$ & $10(10-11)$ & 0,476 \\
\hline ARDS, n (\%) & $7(5,6)$ & $0(0,0)$ & $\mathbf{0 , 0 2 0}$ \\
\hline Sepsis, n (\%) & $89(71,8)$ & $74(78,7)$ & 0,242 \\
\hline Yoğun bakım yatış süresi (gün), ortanca (Ç1-Ç3) & $10(6-15)$ & $13(9-21)$ & $\mathbf{0 , 0 0 1}$ \\
\hline Yoğun bakım mortalitesi, n(\%) & $21(16,9)$ & $23(24,5)$ & 0,170 \\
\hline Ek hastalık varlığı, n (\%) & $106(85,5)$ & $80(85,1)$ & 0,938 \\
\hline \multicolumn{4}{|l|}{ Ek hastalıklar*, n (\%) } \\
\hline Konjestif kalp yetmezliği & $37(29,8)$ & $28(29,8)$ & 0,993 \\
\hline Diabetes mellitus & $38(30,6)$ & $24(25,5)$ & 0,407 \\
\hline Hipertansiyon & $63(50,8)$ & $45(47,9)$ & 0,668 \\
\hline Koroner arter hastalığ 1 & $20(16,1)$ & $17(18,1)$ & 0,703 \\
\hline Atrial fibrilasyon & $21(16,9)$ & $16(17,0)$ & 0,987 \\
\hline Alzheimer & $3(2,4)$ & $5(5,3)$ & 0,295 \\
\hline $\begin{array}{l}\text { AIznebrer } \\
\text { Serebrovasküler olay }\end{array}$ & $4(3,2)$ & $5(5,3)$ & 0,504 \\
\hline $\begin{array}{l}\text { Serebrovaskuler olay } \\
\text { Parkinson }\end{array}$ & $1(0,8)$ & $4(4,3)$ & 0,168 \\
\hline $\begin{array}{l}\text { Kronik böbrek hastalığ } 1 \\
\text { Kronson }\end{array}$ & $11(8,9)$ & $9(9,6)$ & 0,859 \\
\hline $\begin{array}{l}\text { Malignite } \\
\text { Mrom noorek nastigi }\end{array}$ & $11(8,9)$ & $14(14,9)$ & 0,167 \\
\hline Benign prostat hiperplazisi & $10(8,1)$ & $7(7,4)$ & 0,866 \\
\hline \multicolumn{4}{|l|}{ Yatış tanıları*, n (\%) } \\
\hline Kronik obstrüktif akciğer hastalığ & $88(71,0)$ & $70(74,5)$ & 0,567 \\
\hline Kifoskolyoz & $5(4,0)$ & $0(0,0)$ & 0,071 \\
\hline Obezite hipoventilasyon sendromu & $19(15,3)$ & $12(12,8)$ & 0,592 \\
\hline Bronșiektazi & $6(4,8)$ & $7(7,4)$ & 0,421 \\
\hline İntersitisyel akciğer hastalığ & $5(4,0)$ & $2(2,1)$ & 0,701 \\
\hline Kanser & $2(1,6)$ & $6(6,4)$ & 0,078 \\
\hline Pnömoni & $5(4,0)$ & $4(4,3)$ & 0,999 \\
\hline
\end{tabular}

*: Birden fazla ek hastalık ve tanı olan olgu mevcut, NIMV: Noninvaziv mekanik ventilasyon, APACHE: Acute physiology and chronic health evaluation, $\mathrm{PaCO}_{2}$ : Parsiyel karbondioksit basinc1, $\mathrm{PaO}_{2} / \mathrm{FiO}_{2}$ : Parsiyel oksijen basinci/fraksiyone oksijen, SOFA: Sequential organ failure assesstment score, ARDS: Akut solunum sıkıntısı sendromu, SS: Standart sapma, (Ç1-Ç3): 1. ve 3. çeyrek değerleri 
Tablo 5. Erken ve geç NIMV başarısızlığı olan gruplarda NIMV başarısızlık nedenlerinin karşılaştırılması

\begin{tabular}{|c|c|c|c|}
\hline & $\begin{array}{c}\text { Erken NIMV başarısızlığı } \\
(\mathrm{n}=124)\end{array}$ & $\begin{array}{c}\text { Geç NIMV Başarısızlığı } \\
(\mathrm{n}=94)\end{array}$ & $\mathbf{p}$ \\
\hline \multicolumn{4}{|l|}{ NIMV Başarısızlık Nedenleri*, n (\%) } \\
\hline $\mathrm{PaCO}_{2}$ artış1 & $61(49,2)$ & $38(40,4)$ & 0,198 \\
\hline Asidozun derinleşmesi & $71(57,3)$ & $40(42,6)$ & $\mathbf{0 , 0 3 1}$ \\
\hline Asidozun devam etmesi & $86(69,4)$ & $41(43,6)$ & $<0,001$ \\
\hline Solunumsal arrest gelişmesi & $59(47,6)$ & $29(30,9)$ & 0,013 \\
\hline Kardiyak arrest gelişmesi & $37(29,8)$ & $12(12,8)$ & 0,003 \\
\hline Hava yolunu koruyamama & $1(0,8)$ & $9(9,6)$ & 0,003 \\
\hline Ajitasyon/delirium & $9(7,3)$ & $12(12,8)$ & 0,172 \\
\hline Bilinç bulanıklığı & $15(12,1)$ & $23(24,5)$ & $\mathbf{0 , 0 1 7}$ \\
\hline Maske intolereansı & $23(18,5)$ & $26(27,7)$ & 0,110 \\
\hline Hemodinamik instabilite & $26(21,0)$ & $15(16)$ & 0,348 \\
\hline Kusma & $7(5,6)$ & $13(13,8)$ & $\mathbf{0 , 0 3 8}$ \\
\hline Epileptik nöbet & $4(3,2)$ & $5(5,3)$ & 0,504 \\
\hline
\end{tabular}

*: Birden fazla neden olan olgu mevcut, NIMV: Noninvaziv mekanik ventilasyon, $\mathrm{PaCO}_{2}$ : Parsiyel karbondioksit basınc1

Erken ve geç dönemde NIMV başarısızlığı olan gruplarda NIMV başarısızlık nedenleri karşılaştırıldığında (Tablo 5), asidozun derinleşmesi ve devam etmesi, solunumsal/kardiyak arrest gelişmesi, erken dönemde geç döneme göre daha fazla görüldü (sırasıyla, $p=0,031$; $\mathrm{p}<0,001 ; \mathrm{p}=0,013$ ve $\mathrm{p}=0,003)$. Geç dönemde NIMV başarısızlığ 1 olan grupta havayolunu koruyamama, bilinç bulanıklığı ve kusma erken döneme göre daha fazla idi (sırasiyla $\mathrm{p}=0,003 ; \mathrm{p}=0,017$ ve $\mathrm{p}=0,038$ ).

Geç dönemde NIMV başarısızlığı risk faktörlerini incelemek için yapılan çoklu lojistik regresyon analizinde modele ait Ki-kare değeri 44,212 ve $\mathrm{p}<0,001$ idi. Model özetinde Nagelkerke $\mathrm{R}^{2}$ değeri ve Hosmer \& Lemeshow testine ait $\mathrm{p}$ değeri sırasıly 0,246 ve 0,060 idi. Modelin gücü Nagelkerke $\mathrm{R}^{2}$,ye göre çok iyi olmamakla birlikte güncel literatürü tartışmak açısından önemlidir.

Geç dönemde NIMV başarısızlığı gelişmesi için risk faktörleri incelendiğinde, asidozun devam etmesinin NIMV başarısızlığını 4,1 kat (\%95 GA 1,711-9,882; $\mathrm{p}=0,002)$, hava yolunu koruyamamanın 10,4 kat (\%95 GA 1,224-89,264; $\mathrm{p}=0,032)$, bilinç bulanıklığının ise 2,3 kat (\%95 GA 1,023-5,295; p=0,044) arttırdığı görüldü (Tablo 6). Çalışmada geç dönem NIMV başarısızlığı için en önemli risk faktörünün hava yolunu koruyamama olduğu bulundu.

Tablo 6. Geç NIMV başarısızlığı için risk faktörleri

\begin{tabular}{lcc}
\hline & OR (\%95 GA) & p \\
\hline PaCO$_{2}$ artış1 & $3,460(0,975-12,278)$ & 0,055 \\
Asidozun derinleşmesi & $0,600(0,187-1,929)$ & 0,391 \\
Asidozun devam etmesi & $4,112(1,711-9,882)$ & $\mathbf{0 , 0 0 2}$ \\
Solunumsal arrest gelişmesi & $0,842(0,415-1,710)$ & 0,634 \\
Kardiyak arrest gelişmesi & $0,559(0,223-1,398)$ & 0,214 \\
Hava yolunu koruyamama & $10,453(1,224-89,264)$ & $\mathbf{0 , 0 3 2}$ \\
Ajitasyon/delirium & $0,942(0,339-2,620)$ & 0,909 \\
Bilinç bulanıklığ1 & $2,327(1,023-5,295)$ & $\mathbf{0 , 0 4 4}$ \\
Maske intolereansı & $1,772(0,870-3,607)$ & 0,115 \\
Hemodinamik instabilite & $0,626(0,273-1,438)$ & 0,270 \\
Kusma & $1,997(0,655-6,084)$ & 0,224 \\
Epileptik nöbet & $2,139(0,470-9,736)$ & 0,325 \\
\hline
\end{tabular}

NIMV: Noninvaziv mekanik ventilasyon, $\mathrm{PaCO}_{2}$ : Parsiyel karbondioksit basıncı, OR: Odds ratio, GA: Güven aralığı

\section{TARTIŞMA}

NIMV başarısızlığını değerlendiren bu çalışmada olguların yarısında ilk 48 saat içinde başarısızlık görülürken, en sık başarısızlık nedeni arteryel kan gazında asidozun devam etmesi veya derinleşmesi ile parsiyel karbondioksit $\left(\mathrm{PaCO}_{2}\right)$ düzeyinin artması olduğu görüldü. Ayrıca NIMV başarısızlığı olan olgularda yoğun bakım mortalitesi $\% 20$ ve 28 gün mortalitesi $\% 9$ olarak tespit edildi.

Nicolini ve ark. (5) tarafindan yapılan HSY nedeniyle NIMV uygulanan 1809 vakayı içeren çok merkezli, prospektif klinik çalışmada NIMV başarısızlık oranı \%6,6 bildirilmiş olup olguların yaklaşık yarısı erkek ve yaş ortalaması 79 olarak tespit edilmiştir. Çalışmamızda NIMV başarısızlığı saptanan olguların cinsiyet ve yaş dağılımı literatür ile uyumlu bulundu. NIMV başarısını etkileyen hasta ile ilgili faktörlerin başında ek hastalıklar gelir. Çalışmalarda kardiyovasküler hastalıkların NIMV başarısızlığı ile beraberliğinin sık gözlendiği bildirilmiştir $(7,13)$. Bizim çalışmamızda en sık görülen ek hastalıklar sirasiyla hipertansiyon $(\mathrm{n}=108, \% 49,5)$, konjestif kalp yetmezliği $(n=65, \% 29,8)$ ve diabetes mellitus $(n=62$, $\% 28,4)$ idi.

NIMV başarısı için önemli faktörlerden biri de hastanın başlangıçtaki hastalık ağırlık düzeyidir. APACHE II, hastalık şiddeti göstergesi olarak kullanılan skorlama yöntemlerinden biri olup, yapılan çalışmalarda APACHE II değerinin yüksek olması NIMV başarısızlığg ile ilişkili bulunmuştur $(4,6,8,14)$. Confalonieri ve ark. (14) çok merkezli, 1033 KOAH atağı olgusunu içeren çalışmalarında APACHE II skorunun 29'dan fazla olmasının NIMV başarısızlığını ön görmede önemli bir belirteç olduğu tespit etmişlerdir. Hastalık şiddetini gösteren diğer bir belirteç Basitleştirilmiş Akut Fizyoloji Skoru (Simplified Acut Ephysiology Score, SAPS) olup bu skorun 34'ten yüksek olması hipoksemik solunum yetmezliğinde NIMV başarısızlı̆̆ı için bağımsız risk faktörü olarak tanımlanmıştır $(15,16)$. Nicolini ve ark. (5) çalışmalarında SAPS değerinin NIMV başarısızlığı gözlenen olgularda takip süresi boyunca progresif ve anlamlı olarak yükseldiğini tespit etmişlerdir. Merkezimizde hastalık ağırlık göstergesi olarak APACHE II skoru kullanılmakta olup, NIMV başarısızlığı olan olgularda APACHE II ortanca değeri diğer çalışmalarla uyumlu olarak 26 saptand1. 
Rehberlerde NIMV kontrendikasyonları solunumsal ve kardiyak arrest, NIMV tolere edememe, bilinç düzeyinde azalma, masif aspirasyon veya kusma, sekresyonlarını atamama, ciddi hemodinamik bozukluk ve ciddi aritmi olarak belirlenmiştir (17,18). ERS/ATS konsensus bildirgesinde bilinç düzeyinde azalma NIMV için göreceli kontrendikasyon olarak bildirilmiştir. Bilinç düzeyinde azalmaya neden olan karbondioksit yüksekliğinin NIMV etkisiyle düşürülebileceği de ifade edilmiştir (2). Confalonieri ve ark. (14) NIMV uygulama öncesi başarısızlık riskini en çok arttıran faktörün GKS'nin 11 ve altında olması (Odds ratio:4,4) olduğunu tespit etmişlerdir. Ayrıca GKS'nin 12-14 arasında olmasının NIMV başarısızlığını 2,2 kat arttırdığı da tespit edilmiştir. Kaya ve ark. (6) akut hiperkapnik solunum yetmezliğinde NIMV başarısızlığı ile ilişkili faktörleri değerlendirdikleri çalışmalarında GKS düzeyini NIMV başarısız grupta (13 \pm 1.1$)$ başarılı gruba (14 \pm 0.1$)$ göre anlamlı olarak düşük saptamışlardır. Bizim çalışmamızda olguların ortalama GKS değeri 14,3 $\pm 0,1$ idi.

2017 yilında Avrupa ve Amerika Solunum derneklerinin ortak yayınladıkları akut solunum yetmezliğinde noninvaziv ventilasyon klinik uygulama rehberinde NIMV'nin, hiperkapnik KOAH atağında, kardiyojenik pulmoner ödemde, immünsuprese hastada gelişen pnömonide, postoperatif hastada gelişen solunum yetmezliğinde, palyatif bakımda, yüksek riskli hastada ekstübasyon sonrası ve hiperkapnik hastada weaning sürecinde kullanılması önerilmektedir (2). Bhatti ve ark. (19) NIMV uygulanan 1095 hastayı içeren retrospektif çalışmalarında başarısızlık oranını \%10 bulmuş olup, başarısız olan olguların çoğunluğunu KOAH ve pnömoni olgularının oluşturduğu görülmektedir. NIVM başarısızlığının zamanlaması, nedenleri ve risk faktörlerini araştıran bir çalışmada özellikle ARDS'ye bağlı solunum yetmezliğinde erken dönemde NIMV başarısızlığı sık görülürken, akut akciğer ödemine bağlı solunum yetmezliğinde NIMV başarısızlığının nadir görüldüğü belirtilmiştir (8). Türkiye'de NIMV başarısızlığı ile ilgili olarak yapılan çalışmalarda, bizim çalışmamızda da olduğu gibi NIMV başarısızlığı sıklıkla KOAH olgularında gözlenirken, bunu OHS ve kifoskolyoz izlemektedir $(4,6,20)$.

NIMV başlanan hastaların başlangıç AKG değerleri başarı ve başarısızlığı değerlendirmek için önemli bir faktördür. Takiplerde düzelen $\mathrm{pH}$ ve klinik olarak takipnenin gerilemesi NIMV başarısını gösterir. Canfalonieri ve ark. (14) tarafından yapılan çalışmada GKS $<11$, APACHE II $>28$, solunum say1s1 $>29$ /dakika ve $\mathrm{pH}<7,25$ olan olgularda NIMV başarısızlık oranı yüksek bulunmuştur. Kaya ve ark. (6), NIMV başarısızlığında etkili faktörleri inceledikleri çalışmalarında NIMV başarılı ve başarısız hastaların başlangıç AKG değerlerinde anlamlı farklılıklar olmamakla beraber NIMV uygulandiktan 1 saat sonraki AKG'de NIMV başarılı grupta $\mathrm{pH}$ değerini anlamlı olarak yüksek, $\mathrm{PaCO}_{2}$ değerinin ise anlamlı olarak düşük bulmuşlardır. NIMV başarısız grupta ise $\mathrm{pH}$ ve $\mathrm{PaCO}_{2}$ düzeylerinde anlamlı farklılık tespit edilmemiştir. Nicolini ve ark. (5), $1809 \mathrm{KOAH}$ tanılı hastayı 10 yıl boyunca takip ettikleri prospektif çalışmalarında NIMV başarısızlık oranını \%6,6 olarak saptamışlardır. Bu çalışmanın önemli sonuçları olarak ek hastalıkların az olması, daha hafif hastalık şiddeti ve NIMV uygulamanın ilk saatinde AKG değerlerinde düzelme saptanmasını başarının önemli göstergeleri olarak belirtmişlerdir. Buna ek olarak NIMV'nin birinci saatinde $\mathrm{pH}$ değerinde yükselme olmaması da hastane mortalitesi ile yüksek oranda ilişkili bulunmuştur. Bunlara ek olarak diğer çalışmalarda NIMV başarısızlığını etkileyen bağımsız faktör olarak başlangıç ve takiplerdeki $\mathrm{PaO}_{2} / \mathrm{FiO}_{2}$ düzeyinin düşük olması bildirilmektedir (4,8). Bizim çalışmamızda ise en sık karşılaşılan NIMV başarısızlık nedenlerinin asidozun devam etmesi $(n=127, \% 58,3)$ veya derinleşmesi $(n=111$, $\% 50,9)$ ile $\mathrm{PaCO}_{2}$ düzeyinin artması $(\mathrm{n}=99, \% 45,4)$ olduğu görüldü.

NIMV başarısızlığı, ilk 48 saatte erken başarısızlık ve 48 saatten sonra geç başarısızlık olarak değerlendirilmektedir. NIMV başarısızlıklarının yaklaşık \%65'i erken dönemde görülür $(8,14)$. Bizim olgularımızın \%56'sında erken başarısızlık görülmekte idi. Çalışmalarda geç başarısızlık oranı yaklaşık \%15 olarak bildirilmekte olup erken ve geç NIMV başarısızlık grubu karşılaştırıldı̆̆ında $\mathrm{pH}$ ve $\mathrm{PaCO}_{2}$ değerleri arasında anlamlı farklılık tespit edilmemektedir $(7,8)$. Bizim çalışmamızda ise $\mathrm{PaCO}_{2}$ artışının erken ve geç dönemde NIMV başarısızlığını etkilemediği saptanırken, asidozun devam etmesi ve derinleşmesinin erken dönemde daha sık görüldüğü bulundu. Bunun yanında geç NIMV başarısızlığı görülen grupta pnömoni sıklığı ve hastane mortalitesi daha fazla görülmektedir $(7,8)$. Çalışmamızda erken ve geç dönemde NIMV başarısızlığı olan grupta yatış tanıları ve ek hastalıklar karşılaştırıldığında istatistiksel olarak anlamlı farklılık saptanmadı. Yakın zamanda yapılan çalışmalardan farklı olarak çalışmamızda erken ve geç dönemde NIMV başarısızlığı olan gruplarda mortalite açısından farklılık saptanmadı. Erken ve geç dönemde NIMV başarısızlığı olan gruplardaki hastaların farklılıkları, NIMV ekipman seçimi ve uygulayan ekibin deneyimi bu durumu açıklayabilir. Hastaların kliniğinden bağımsız olarak çalışmamızda, NIMV başarısızlık sebepleri asidozun devam etmesi/derinleşmesi ve $\mathrm{PaCO}_{2}$ düzeyinde artış olarak bulundu.

Confalonieri ve ark. (14) tarafından yapılan çalışmada başarısızlık erken ve geç dönem NIMV başarısızlığı olarak ayrılmamış olsa da, KOAH olgularında $\mathrm{GKS} \leq 11$ olmasının NIMV başarısızlığını 4,4 kat, APACHE II skorunun $\geq 29$ olmasının 3,3 kat ve $\mathrm{pH}<7,25$ olmasının 1,9 kat artırdığ 1 bildirilmiştir. Çalışmamızda ise geç dönem NIMV başarısızlığ 1 için risk faktörleri incelendiğinde; geç dönem NIMV başarısızlığını havayolunu koruyamamanın 10,4 kat, asidozun devam etmesinin 4,1 kat ve bilinç bulanıklığının ise 2,3 kat artırdı ğı saptandı.

Çalışmamızın bazı sınırlamaları mevcuttur. Öncelikle çalışmamız tek merkezli retrospektif bir çalışma olarak planlandığından elde edilen bilgilerin genelleştirilmesi uygun olmayabilir. Ancak mevcut hastaların aynı göğüs hastalıkları ve yoğun bakım hekimleri tarafindan aynı protokol ile takip edilmesi nedeniyle çalışma sonuçlarının benzer hastalar için değerli olabileceği düşünülmektedir.

\section{SONUC}

Günümüzde, entübasyon/re-entübasyon oranlarını azaltması, hastane yatış süresini kısaltması ve mortaliteyi azaltması nedeniyle akut solunum yetmezliğinde NIMV kullanım oranı ve uygulama yerleri artmaktadır. Artan hasta sayısı ve deneyimle birlikte günlük pratikte 
kullanımı yaygınlaşan NIMV'nin başarısızlığını öngörmek ve buna yönelik önlemler almak çok önemlidir. Bu çalışmada, NIMV başarısızlığının yarısından fazlasının ilk 48 saatte olduğu ve en önemli nedeninin asidozun devam etmesi veya derinleşmesi ile $\mathrm{PaCO}_{2}$ düzeyinin artması olduğu görüldü. NIMV başarısızlığı olan olgularda beklenildiği üzere mortalite yüksektir ancak bu çalışmada taburculuk sonrası ilk 28 gün mortaliteleri \%9 saptanmıştır. $\mathrm{Bu}$ nedenle NIMV başarısızlığı olan olguların yoğun bakım taburculuğu sonrasında yakın takip edilmesinin faydalı olacağı düşünülmektedir.

\section{KAYNAKLAR}

1. Keenan SP, Sinuff T, Burns KE, Muscedere J, Kutsogiannis J, Mehta S, et al. Clinical practice guidelines for the use of noninvasive positive-pressure ventilation and noninvasive continuous positive airway pressure in the acute care setting. CMAJ. 2011;183(3):E195-214.

2. Rochwerg B, Brochard L, Elliott WM, Hess D, Hill SN, Nava S, et al. Official ERS/ATS clinical practice guidelines: noninvasive ventilation for acute respiratory failure. EurRespir J. 2017;50(2):1602426.

3. Garpestad E, Brennan J, Hill NS. Noninvasive ventilation for critical care. Chest. 2007;132(2):71120.

4. Çiledağ A, Kaya A, Erçen Diken Ö, Önen ZP, Şen E, Demir N. The risk factors for late failure of noninvasive mechanical ventilation in acute hypercapnic respiratory failure. Tuberk Toraks. 2014;62(3):177-82.

5. Nicolini A, Ferrera L, Santo M, Ferrari-Bravo M, Del Forno M, Sclifò F. Noninvasive ventilation for hypercapnic exacerbation of chronic obstructive pulmonary disease: factors related to noninvasive ventilation failure. Pol Arch Med Wewn. 2014;124(10):525-31.

6. Kaya A, Çiledağ A, Çaylı İ, Önen ZP, Şen E, Gülbay B. Associated factors with non-invasive mechanical ventilation failure in acute hypercapnic respiratory failure. Tuberk Toraks. 2010;58(2):128-34.

7. Moretti M, Cilione C, Tampieri A, Fracchia C, Marchioni A, Nava S. Incidence and causes of noninvasive mechanical ventilation failure after initial success. Thorax. 2000;55(10):819-25.

8. Ozyilmaz E, Ozsancak Ugurlu A, Nava S. Timing of noninvasive ventilation failure: causes, risk factors, and potential remedies. BMC Pulm Med. 2014;14:19.

9. Celikel T, Sungur M, Ceyhan B, Karakurt S. Comparison of noninvasive positive pressure ventilation with standard medical therapy in hypercapnic acute respiratory failure. Chest. 1998;114(6):1636-42.
10. Phua J, Kong K, Lee KH, Shen L, Lim TK. Noninvasive ventilation in hypercapnic acute respiratory failure due to chronic obstructive pulmonary disease vs. other conditions: effectiveness and predictors of failure. Intensive Care Med. 2005;31(4):533-9.

11. Bach JR, Brougher P, Hess DR, Hill NS, McIntyre N, Pearson D, et al. Consensus statement: noninvasive positive pressure ventilation. Respir Care. 1997;42:365-9.

12. American Thoracic Society. Standards for the diagnosis and care of patients with chronic obstructive pulmonary disease. Am J Respir Crit Care Med. 1995;152(5 Pt 2):S77-121.

13. Scala R, Bartolucci S, Naldi M, Rossi M, Elliott MW. Co-morbidity and acute decompensations of COPD requiring non-invasive positive-pressure ventilation. Intensive Care Med. 2004;30(9):1747-54.

14. Confalonieri M, Garuti G, Cattaruzza MS, Osborn JF, Antonelli M, Conti G, et al. A chart of failure risk for noninvasive ventilation in patients with COPD exacerbation. Eur Respir J. 2005;25(2):348-55.

15. Antonelli M, Conti G, Moro ML, Esquinas A, Gonzalez-Diaz G, Confalonieri M, et al. Predictors of failure of noninvasive positive pressure ventilation in patients with acute hypoxemic respiratory failure: a multi-center study. Intensive Care Med. 2001;27(11):1718-28.

16. Antonelli M, Conti G, Esquinas A, Montini L, Maggiore SM, Bello G, et al. A multiple-center survey on the use in clinical practice of noninvasive ventilation as a first-line intervention for acute respiratory distress syndrome. Crit Care Med. 2007;35(1):18-25.

17. Diagnosis and Assesment. In: Decramer M, Vestbo J, editors. Global Strategy for the Diagnosis, Management and Prevention of COPD, Global Initiative For Chronic Obstructive Lung Disease updated 2014. Content Ed Net; 2014. p. 9-17.

18. Kocabaş A, Atış S, Çöplü L, Erdinç E, Ergan B, Gürgün A, et al. Kronik Obstrüktif Akciğer Hastalığı (KOAH) Koruma, Tanı ve Tedavi Raporu. Turk Thorac J. 2014;15(suppl 2):19-25.

19. Bhatti H, Ramdass A, Cury JD, Jones LM, Shujaat A, Louis M, et al. Operator dependent factor simplicated in failure of non-invasive positive pressure ventilation (NIPPV) for respiratory failure. Clin Respir J. 2017;11(6):901-5.

20. Bacakoğlu F, Taşbakan MS, Kaçmaz Başoğlu Ö, Öz AT, Ürkmez S, Midilli M, et al. The factors affecting noninvasive mechanical ventilation failure in COPD exacerbations. Turk J Med Sci. 2012;42(1):103-12. 